\title{
Bleomycin induces cellular senescence in alveolar epithelial cells
}

\author{
K. Aoshiba, T. Tsuji, A. Nagai
}

Bleomycin induces cellular senescence in alveolar epithelial cells. K. Aoshiba, T. Tsuji, A. Nagai. C) ERS Journals Ltd 2003.

ABSTRACT: Cellular senescence is a state of irreversible growth arrest. In this paper the authors examined whether bleomycin, an agent that causes pulmonary fibrosis, induces the senescence of alveolar epithelial cells.

Type II-like alveolar epithelial (A549) cells or rat primary type II cells were exposed to bleomycin and then evaluated for markers of cellular senescence. Bleomycin was also administered intratracheally in C57BL/6 mice.

The authors found that exposure to bleomycin induced cellular senescence in A549 cells and rat primary type II cells. The senescence was characterised by a dose- and time-dependent increase in senescence-associated $\beta$-galactosidase activity, senescenceassociated changes in cell morphology, an increase in cell size and lysosomal mass, the overexpression of p21 protein, and irreversible growth arrest. The intratracheal injection of bleomycin in mice induced an increase in senescence-associated $\beta$-galactosidase activity in type II epithelial cells, reaching a maximum at day 7 .

These results suggest that bleomycin induces a phenotype that is indistinguishable from that of senescence in alveolar epithelial cells. The induction of epithelial senescence by bleomycin may contribute to the pathway of impaired re-epithelialisation leading to pulmonary fibrosis.

Eur Respir J 2003; 22: 436-443.
First Department of Medicine, Tokyo Women's Medical University, Tokyo, Japan.

Correspondence: K. Aoshiba

First Department of Medicine

Tokyo Women's Medical University

8-1 Kawada-cho

Shinjuku-ku 162-8666

Japan

Fax: 81353795457

E-mail:kaoshiba@chi.twmu.ac.jp

Keywords: Cell aging

interstitial lung diseases

pulmonary fibrosis

Received: February 42003

Accepted after revision: April 302003
Pulmonary fibrosis is characterised by sequential acute lung injury with progressive fibrosis and architectural distortion [1]. The original hypothesis for the pathogenesis of pulmonary fibrosis was that chronic inflammation stimulates fibroblasts [2, 3]. However, a newer hypothesis proposes that epithelial injury and impaired regeneration are sufficient to stimulate fibroblasts, without the need for ongoing inflammation [4]. This hypothesis suggests that impaired reepithelialisation, following lung injury, triggers the process of pulmonary fibrosis. An important pathological feature in patients with pulmonary fibrosis is a marked loss of type I cells without appropriate re-epithelialisation, while hyperplasia of abnormal type II cells occurs in other areas [4-7]. The absence of re-epithelialisation is thought to induce the migration of activated fibroblasts, through defects in the epithelium from the interstitial to the intraluminal compartments, leading to pulmonary fibrosis [7]. However, the mechanism of the impaired re-epithelialisation in pulmonary fibrosis is not well understood.

Cellular senescence is a state where cells can no longer divide, despite the presence of appropriate growth factors [8]. This state can be induced either by telomere shortening (replicative senescence) or by telomere-independent signals, such as deoxyribonucleic acid (DNA) damage and oxidative stress (stress-induced senescence). The state of cellular senescence is associated with the following: irreversible growth arrest; a distinct flat, and enlarged cell morphology; an increase in senescence-associated $\beta$-galactosidase (SA $\beta$-gal) activity; and the expression of cell cycle inhibitors, such as p16 ${ }^{\mathrm{INK} 4 a}$ and $\mathrm{p} 21^{\mathrm{CIP} 1 / \mathrm{WAF} 1 / \mathrm{Sdi} 1}$ [8-10]. Ample evidence indicates cellular senescence is important for phenotypic aspects of aging, such as delayed wound healing, a reduced immune response, and thinning of the skin [11]. Recent studies have also indicated that cellular senescence plays an important role in the pathogenesis of chronic diseases, such as liver cirrhosis and atherosclerosis [12, 13]. However, the role of cellular senescence in pulmonary fibrosis has not been examined. The authors hypothesised that when epithelial cells reach the senescence stage, epithelial regeneration ceases and fibrosis is promoted. In the present study, the authors examined whether bleomycin, an agent that causes pulmonary fibrosis, induces the senescence of alveolar epithelial cells.

\section{Materials and methods}

\section{Animal treatment}

The animal protocol was approved by the Animal Care and Use Committee of Tokyo Women's Medical University. An animal model for bleomycin-induced pulmonary fibrosis was generated, as described previously [14]. The mice were anaesthetised with an intraperitoneal injection of sodium pentobarbital (Abbott Lab., North Chicago, IL, USA) followed by the intratracheal administration of $50 \mu \mathrm{L}$ of a phosphate-buffered saline (PBS) solution containing bleomycin hydrochloride $\left(5 \mathrm{mg} \cdot \mathrm{Kg}^{-1}\right.$ body weight; Nippon Kayaku, Co., Tokyo, Japan). At days 1, 4, 7, and 21 after the bleomycin injection, the mice were intraperitoneally treated with $30 \mu \mathrm{g}$ of bromodeoxyuridine (BrdU); $4 \mathrm{~h}$ later, they were sacrificed using an intraperitoneal injection of a pentobarbital overdose. The lungs were removed, inflated by manual instillation with $50 \%$ OCT compound (Tissue-Tek $\mathbb{R}$; Sakura Finetechnical Co. Ltd, Tokyo, Japan) quickly frozen, and sectioned $(3 \mu \mathrm{m})$. 


\section{Cell cultures and bleomycin treatment}

The alveolar type II-like epithelial cell line, A549 (ATCC \#CCL-185), was maintained in Dulbecco's modified Eagle's medium (DMEM) containing 10\% foetal calf serum (FCS). The cells $\left(10^{4}\right.$ cells $\left.\cdot \mathrm{cm}^{-2}\right)$ between passages 27 and 35 were plated onto 8-well-chamber slides or 35 or $60 \mathrm{~mm}$ tissue culture plates precoated with type I collagen (Vitrogen ${ }^{\mathrm{TM}}$, Cohesion, Palo Alto, CA, USA) and grown in the above medium. Once they reached $50 \%$ confluence, the cells were rinsed three times with PBS and incubated with DMEM containing $0.1 \%$ FCS with or without bleomycin $(0.1-$ $50 \mu \mathrm{g} \cdot \mathrm{mL}^{-1}$ ) for the indicated periods.

Primary rat type II alveolar epithelial cells were isolated from adult male Sprague-Dawley rats, weighing $250 \mathrm{~g}$, and maintained in DMEM containing $20 \%$ FCS, as previously described [15]. The primary cells were studied at day 2 of the culture, a time at which they are type II cell-like as judged by accepted morphological and biochemical criteria [15]. The primary cell preparations were of $>90 \%$ purity as assessed by modified papanicolaou staining and $>90 \%$ viability as assessed by trypan blue staining. The type II cells were exposed to bleomycin in DMEM containing 20\% FCS because serum depletion killed the cells.

\section{Cell proliferation analysis}

After $120 \mathrm{~h}$ of bleomycin treatment, the A549 cells in the 8-well-chamber slides were rinsed three times with PBS and incubated with DMEM containing either 0.1\% FCS or $10 \%$ FCS. After $48 \mathrm{~h}$, the cells were pulse-labelled with $10 \mu \mathrm{M}$ of BrdU for $60 \mathrm{~min}$, the cells that had incorporated BrdU were detected using immunocytochemistry, as described below.

\section{Cell size analysis}

The cells in the 8-well-chamber slides were fixed with $3 \%$ paraformaldehyde and stained with an eosin solution. Digitised video images of the cells were captured using an Olympus BX60 microscope (Olympus Optical Co., Ltd, Tokyo, Japan) with an Olympus DP50 CCD camera, and sent to an Olympus imaging microscopic workstation (CUSL2G40; Olympus Optical Co., Ltd) equipped with a computer running Microsoft Windows 98 and a computerised color image analysis software system (Win Roof Version 3.5, Mitani Corporation, Fukui, Japan). Each image was then subjected to operations that measured the cell size. The sizes of 300 cells from one well were averaged.

\section{Lysosomal mass analysis}

Morphological examination of the lysosomal mass was performed as previously described [16]. Cells in the 8well-chamber slides were pretreated with $3 \times 10^{-7} \mathrm{M}$ of bafilomycin A1 (Sigma, St. Louis, MO, USA) or the vehicle dimethyl sulfoxide alone for $15 \mathrm{~min}$ at $37^{\circ} \mathrm{C}$ and then incubated with $5 \mu \mathrm{g} \cdot \mathrm{mL}^{-1}$ of acridine orange (Sigma) for 10 min. After washing with PBS, the coverslips were mounted on slides and viewed immediately under an Olympus BX60 microscope using an Olympus longpass filter set comprised of a bandpass $450-490 \mathrm{~nm}$ exciter, a $510 \mathrm{~nm}$ dichroic mirror, and a long pass $520 \mathrm{~nm}$ emitter.

\section{Senescence-associated $\beta$-galactosidase}

SA $\beta$-gal staining was performed according to a previously described method [17], with slight modifications. Cell samples on 8-well-chamber slides were fixed with $2 \%$ formaldehyde and $0.2 \%$ glutaraldehyde in PBS for $5 \mathrm{~min}$ at room temperature. Frozen lung tissue sections were fixed with $0.2 \%$ glutaraldehyde in PBS for $5 \mathrm{~h}$ at $4{ }^{\circ} \mathrm{C}$. The slides were rinsed with $\mathrm{PBS}$ and incubated with a SA $\beta$-gal staining solution containing $40 \mathrm{mM}$ sodium citrate ( $\mathrm{pH} 6.0), 150 \mathrm{mM}$ sodium chloride, $5 \mathrm{mM}$ potassium ferricyanide, $5 \mathrm{mM}$ of potassium ferrocyanide, $2 \mathrm{mM}$ magnesium chloride, and $1 \mathrm{mg} \cdot \mathrm{mL}^{-1}$ of (5-bromo-4-chloro-3-indoyl $\beta$-D galactoside (X-gal)). Some of the slides were then immunostained as described below.

An assessment of SA $\beta$-gal intensity in relation to fibrosis was performed semi-quantitatively using lung tissue sections obtained from mice at 21 days after bleomycin treatment. For each slide, five fields of the fibrotic area and five fields of the nonfibrotic area were selected. For each field, the SA $\beta$-gal intensity was graded: $0=$ no staining, $1=$ weak staining, $2=$ moderate staining, and $3=$ intense staining. The average grade of SA $\beta$-gal intensity was obtained for both the fibrotic and nonfibrotic areas.

\section{Immunohistochemistry and immunocytochemistry}

After SA $\beta$-gal staining, tissue sections were processed for routine immunohistochemistry. The primary antibodies were rabbit polyclonal antilaminin (1:50 dilution; Sigma), mouse monoclonal antipancytokeratin (1:100 dilution; Sigma), rabbit polyclonal antisurfactant protein A (SP-A; 1:100, Santa Cruz Biotechnology Inc., Santa Cruz, CA, USA), rat monoclonal antimouse CD31 (1:25, Research Diagnostics Inc., Flanders, NJ, USA), rat monoclonal antimouse CD45 (1:100, Pharmingen, San Diego, CA), and mouse monoclonal anti-BrdU (1:100, Chemicon International, Temecula, CA, USA). For immunostaining with anti-BrdU, the slides were pretreated with $3 \mathrm{~N} \mathrm{HCl}$ for $30 \mathrm{~min}$ and neutralised with $0.1 \mathrm{M}$ borax buffer, $\mathrm{pH} 8.5$, for $10 \mathrm{~min}$. The primary antibody was reacted with biotinylated anti-IgG conjugated with horseradish peroxidase (HRP)-labelled polymer (EnVison+ peroxidase; DAKO Japan, Kyoto, Japan). Immunoreactants were visualised by 3,3'-diaminobenzidine and counterstained with a nuclear fast red solution. For the immunocytochemistry, cell samples on 8-well-chamber slides were fixed in $70 \%$ ethanol at $-20^{\circ} \mathrm{C}$ for $10 \mathrm{~min}$ and incubated with $0.3 \% \mathrm{H}_{2} \mathrm{O}_{2}$ for $5 \mathrm{~min}$, followed by incubation with $3 \%$ bovine serum albumin in PBS for $30 \mathrm{~min}$. The slides were treated with $3 \mathrm{~N} \mathrm{HCl}$ for $30 \mathrm{~min}$, neutralised with $0.1 \mathrm{M}$

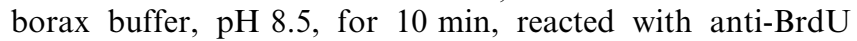
antibody, and processed as above.

Tissue sections double-stained for SA $\beta$-gal activity and either SP-A, pancytokeratin, or CD31 antigen were assessed semiquantitatively. For each slide, 10 microscopic fields were randomly selected. For each field, the number of cells positive for each antigen and the number of cells positive for each antigen with SA $\beta$-gal activity were counted. The average percentage of cells positive for each antigen and the SA $\beta$-gal activity in the population of cells positive for each antigen was calculated.

\section{Immunoblot analysis}

Cell lysates were fractionated by sodium docecylsulfatepolyacrylamide gel electrophoresis (SDS-PAGE), transferred 
to polyvinylidene difluoride membrane, and probed using mouse monoclonal anti-p21 antibody (1:400; Santa Cruz) or rabbit polyclonal anti-actin $(1: 2,500$; Sigma). The primary antibodies were detected using a horseradish peroxidase (HRP)-conjugated antibody, which in turn was visualised by enhanced chemiluminescence (SuperSignal ${ }^{\mathrm{TM}}$, Pierce, Rockford, IL, USA).

\section{Statistical analysis}

All data are expressed as the mean \pm SEM. Differences were examined for significance using an analysis of variance and the Scheffe test or with a two-tailed, unpaired t-test, as appropriate.

\section{Results}

Treatment of A549 cells and primary rat type II cells with bleomycin induces cellular senescence

To determine whether bleomycin induces cellular senescence in lung epithelial cells, the authors treated alveolar type II-like epithelial (A549) cells with various concentrations of bleomycin. Because bleomycin at concentrations of $100 \mu \mathrm{g} \cdot \mathrm{mL}^{-1}$ or higher caused the death of $>20 \%$ of the A549 cells, as determined by trypan blue staining, the authors treated the cells with bleomycin at sublethal concentrations of $\leqslant 50 \mu \mathrm{g} \cdot \mathrm{mL}^{-1}$. When A549 cells were treated with $50 \mu \mathrm{g} \cdot \mathrm{mL}^{-1}$ of bleomycin for $120 \mathrm{~h}$ they exhibited a phenotype that is typical of cellular senescence, as judged by an increase in SA $\beta$-gal activity (fig. 1b); a distinct, flat, and enlarged morphology (fig. 1d); an increase in lysosomal mass (fig. 1f); and irreversible growth inhibition (fig. 1h) [8, 16-18]. Quantitative analyses for cellular senescence showed that the treatment of A549 cells with bleomycin caused a dose-dependent and a time-dependent increase in SA $\beta$-gal activity (fig. $2 \mathrm{a}$ and b), a five-fold increase in cell size (fig. 2c), and a dose-dependent inhibition of cell growth (fig. 2d). As shown in figure $2 b$, $>95 \%$ of the A549 cells expressed SA $\beta$-gal activity after treatment with $50 \mu \mathrm{g} \cdot \mathrm{mL}^{-1}$ of bleomycin for $120 \mathrm{~h}$. An immunoblot analysis also showed that the treatment of A549 cells with bleomycin caused a dose-dependent increase in the expression of $\mathrm{p} 21^{\mathrm{CIP} 1 / \mathrm{WAF} 1 / \mathrm{Sdi} 1}$ protein, a cyclindependent kinase inhibitor that mediates cellular senescence in many types of cells (fig. 3) [9, 19]. The A549 cell is a lung cancer cell line which may not reflect the senescence property of normal alveolar epithelial cells. However, treatment of rat primary type II cells with bleomycin also caused an increase in SA $\beta$-gal activity and a flat and enlarged morphology (fig. 4), suggesting that bleomycin induces senescence of primary type II cells. However, the authors do not completely exclude the possibility that the senescent phenotype of alveolar epithelial cells after bleomycin treatment reflects a change from the type II to type I phenotype. Taken together, these results indicate that treatment with bleomycin induces a phenotype that is indistinguishable from that of cellular senescence in alveolar epithelial cells.

Intratracheal injection of bleomycin causes an increase in senescence-associated $\beta$-galactosidase activity in alveolar epithelial cells in vivo

To determine whether bleomycin induces cellular senescence in alveolar epithelial cells in vivo, lung tissue sections obtained from mice that had received an intratracheal
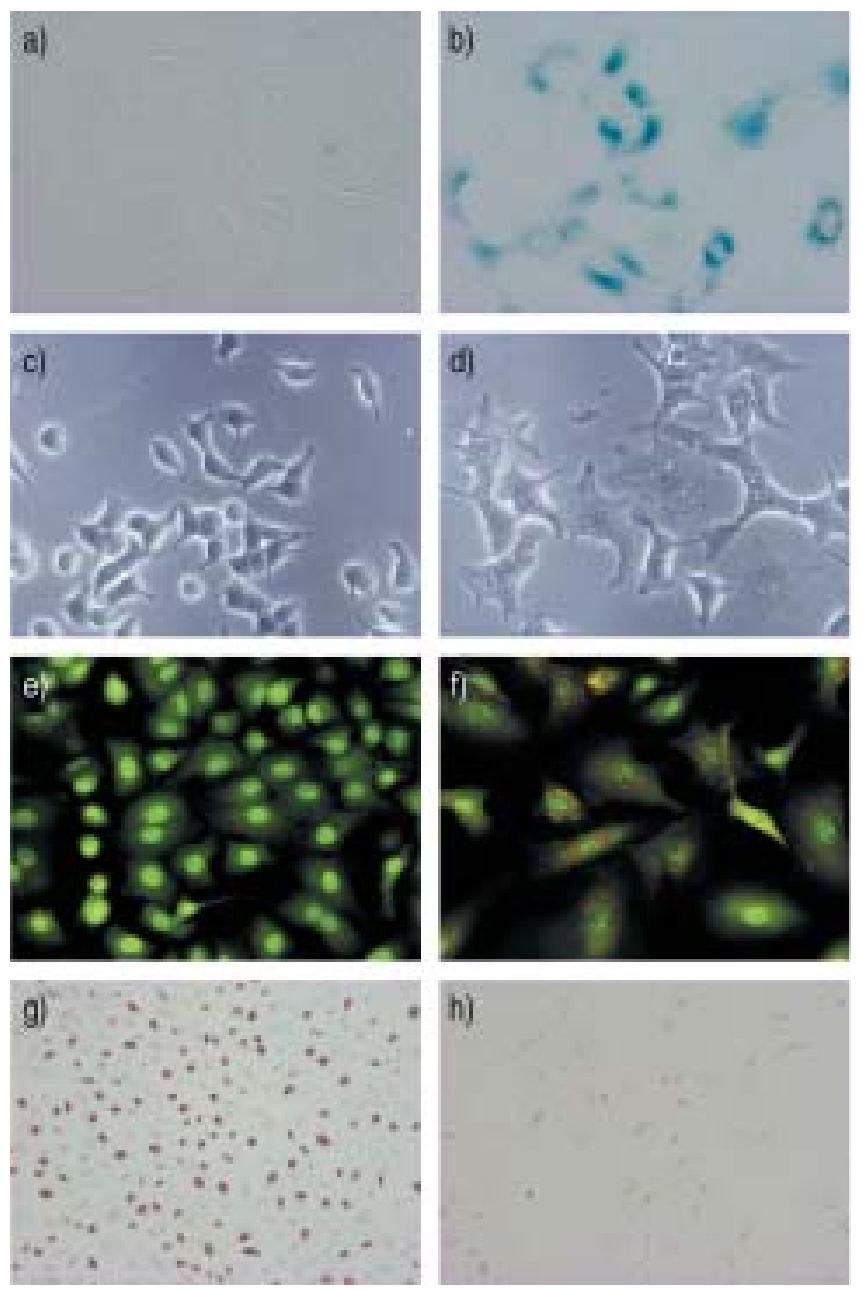

Fig. 1.-Senescent phenotype of A549 cells treated with bleomycin. A549 cells were treated without (a, c, e, and g) or with bleomycin $\left(50 \mu \mathrm{g} \cdot \mathrm{mL}^{-1}\right)(\mathrm{b}, \mathrm{d}, \mathrm{f}$, and $\mathrm{h})$ for $120 \mathrm{~h}$ and examined for markers of cellular senescence. Staining for senescence-associated $\beta$-galactosidase activity $(\mathrm{a}, \mathrm{b})$. Cell morphology (c, d) characterised by flat, enlarged cells, after treatment with bleomycin (d). Lysosome staining with acridine orange $(e, f)$ shows a marked increase in the number and size of lysosomes (orange fluorescence) in cells after treatment with bleomycin (f). The orange fluorescence disappeared when the A549 cells were pretreated with the lysosome inhibitor bafilomycin A1 prior to bleomycin exposure (photographs not shown), confirming its selective lysosomal localisation. The green fluorescence is emitted by the binding of acridine orange to nucleic acids. Anti-bromodeoxyuridine (BrdU) immunostaining of A549 cells treated with (h) or without (g) bleomycin, rinsed with phosphate-buffered saline, and then stimulated with $10 \%$ foetal calf serum (FCS) for $48 \mathrm{~h}$. During the last $60 \mathrm{~min}$ of the stimulation period, the cells were pulse-labelled with BrdU. Treatment with bleomycin abolished the incorporation of BrdU by cells stimulated with FCS (h), indicating that bleomycin causes irreversible growth arrest. These photomicrograph are representative of the results obtained from three experiments.

injection of bleomycin were examined using SA $\beta$-gal staining. Before the bleomycin injection (day 0), SA $\beta$-gal staining was almost negative in lung cells (fig. 5a and 5f) other than alveolar macrophages (fig. 5n), which are enriched with lysosomal $\beta$-galactosidase [20]. After the bleomycin injection, the number of lung cells that stained positive for SA $\beta$-gal increased at day 4 or thereafter (fig. $5 \mathrm{c}-5 \mathrm{e}, 5 \mathrm{~h}-5 \mathrm{j}$ ). The SA $\beta$-gal-stained cells tended to be localised within collapsed or fibrotic lung lesions (fig. 5i and 5j). An immunohistochemical analysis using anti-pancytokeratin, anti-SP-A, anti-CD31, and anti-CD45 demonstrated that the SA $\beta$-gal-stained cells 

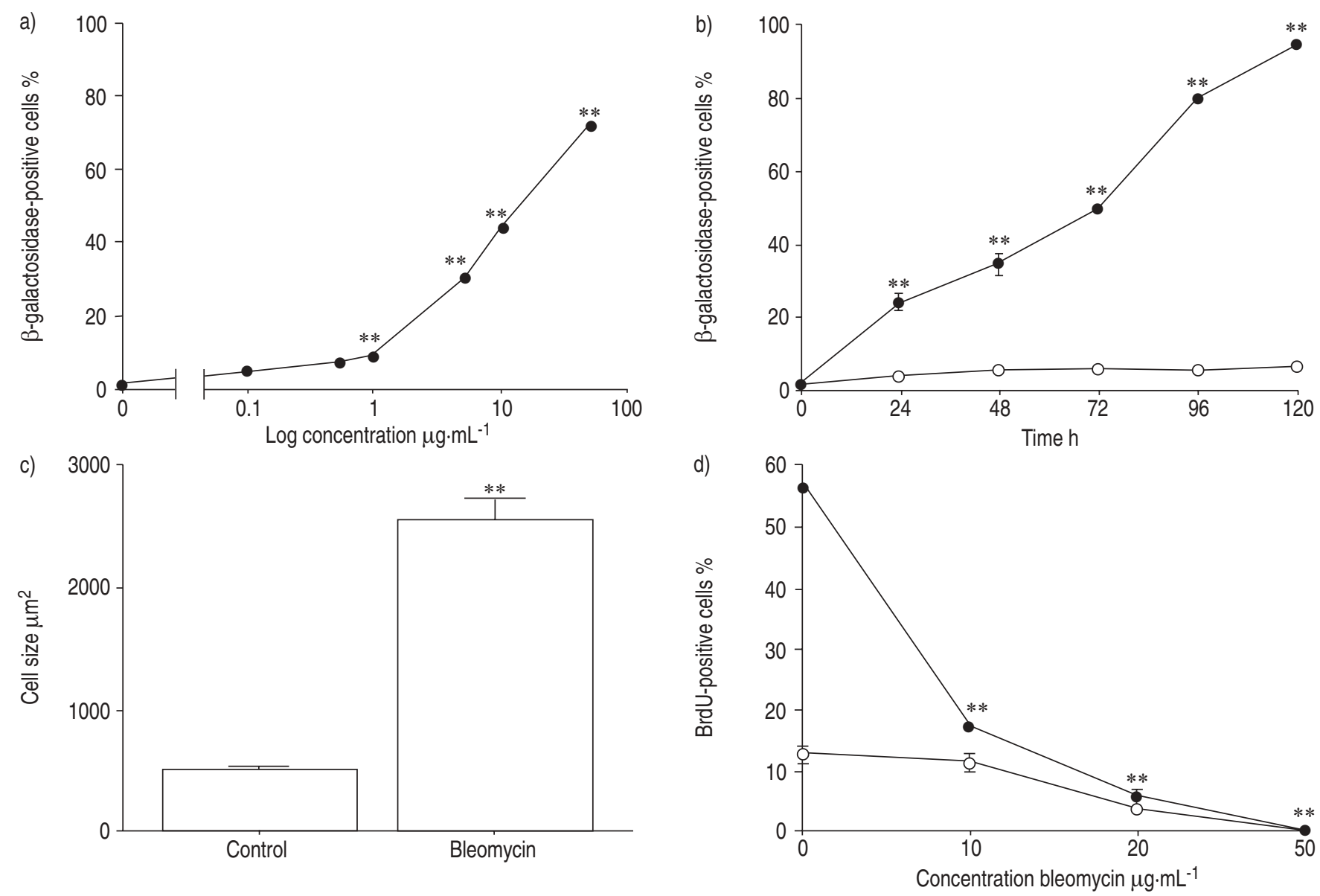

Fig. 2. - Quantitative analyses of cellular senescence in A549 cells treated with bleomycin. a) Staining for senescence-associated $\beta$-galactosidase activity. A549 cells were treated with or without various concentrations of bleomycin for $96 \mathrm{~h}$ or b) with $(\bullet)$ or without $(\bigcirc) 50 \mu \mathrm{g} \cdot \mathrm{mL}^{-1}$ of bleomycin for various periods of time. c) Size of A549 cells treated with or without $50 \mu \mathrm{g} \cdot \mathrm{mL}^{-1}$ of bleomycin for $120 \mathrm{~h}$. d) Incorporation of bromodeoxyuridine (BrdU) by A549 cells. A549 cells were treated with or without various concentrations of bleomycin for 120 h, rinsed with phosphate-buffered saline and incubated with $0.1 \%$ foetal calf serum (FCS; $\bigcirc$ ) or $10 \%$ FCS $(\bullet)$ for $48 \mathrm{~h}$. During the last $60 \mathrm{~min}$ of the incubation, the cells were pulse-labelled with $10 \mu \mathrm{M}$ of BrdU; cells that had incorporated BrdU were detected using immunocytochemistry. **: $\mathrm{p}<0.01$ versus cells not treated with bleomycin. All data are presented as mean \pm SEM for four samples. The results are representative of of two out of three experiments.

were alveolar epithelial cells (fig. 5k and 51), particularly type II cells (fig. 5m), and alveolar macrophages (fig. 5o), but not endothelial cells (photographs not shown). As expected, the SA $\beta$-gal-stained cells had not incorporated BrdU at any of the time points examined (fig. 5p). After injection of PBS alone, the number of cells positive for SA $\beta$-gal did not increase (data not shown). A semi-quantitative analysis also showed that the incidence of alveolar epithelial cells and type II cells positive for SA $\beta$-gal staining reached a maximum at

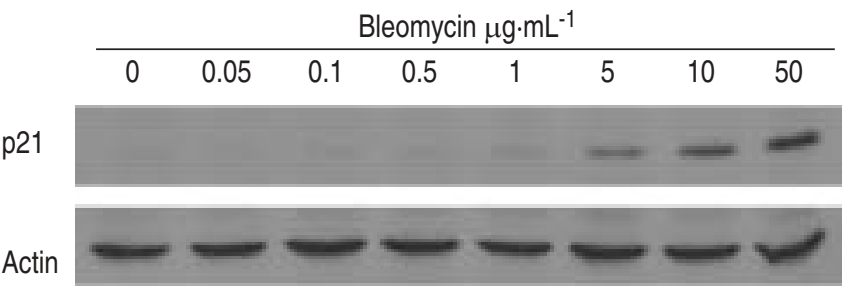

Fig. 3. - An immunoblot analysis of $\mathrm{p} 21^{\mathrm{CIP} 1 / \mathrm{WAF} 1 / \mathrm{Sdi} 1}$ protein after treatment with bleomycin. A549 cells were treated with various concentrations of bleomycin for $120 \mathrm{~h}$. The cell lysate $(50 \mu \mathrm{g}$ per lane) was analysed using immunoblotting with anti-p21 or anti-actin antibodies. The results are representative of two experiments. day 7 and an increase in the incidence of the positive cells was maintained for at least 21 days (fig. 6a). In this analysis, SP-A positive cells may have in addition included nonciliated bronchiolar cells which also express SP-A [21]. In lungs of mice at day 21 after bleomycin treatment, the score of SA $\beta$-gal intensity was much higher in the fibrotic area than in the nonfibrotic area (fig. 6b), suggesting that cellular senescence may be involved in pulmonary fibrogenesis.

\section{Discussion}

Although recent evidence indicates that epithelial regeneration is impaired in pulmonary fibrosis, the responsible mechanism is unknown [4]. The present study demonstrated that treatment with bleomycin induces a phenotype that is indistinguishable from that of senescence in alveolar epithelial cells in vitro and in vivo. These results suggest that cellular senescence may be responsible for the impaired epithelial regeneration that occurs following bleomycin-induced lung injury.

Cellular senescence is a state of irreversible growth arrest which is characterised by distinct morphological and biochemical changes $[9,10]$. This state is induced either by 

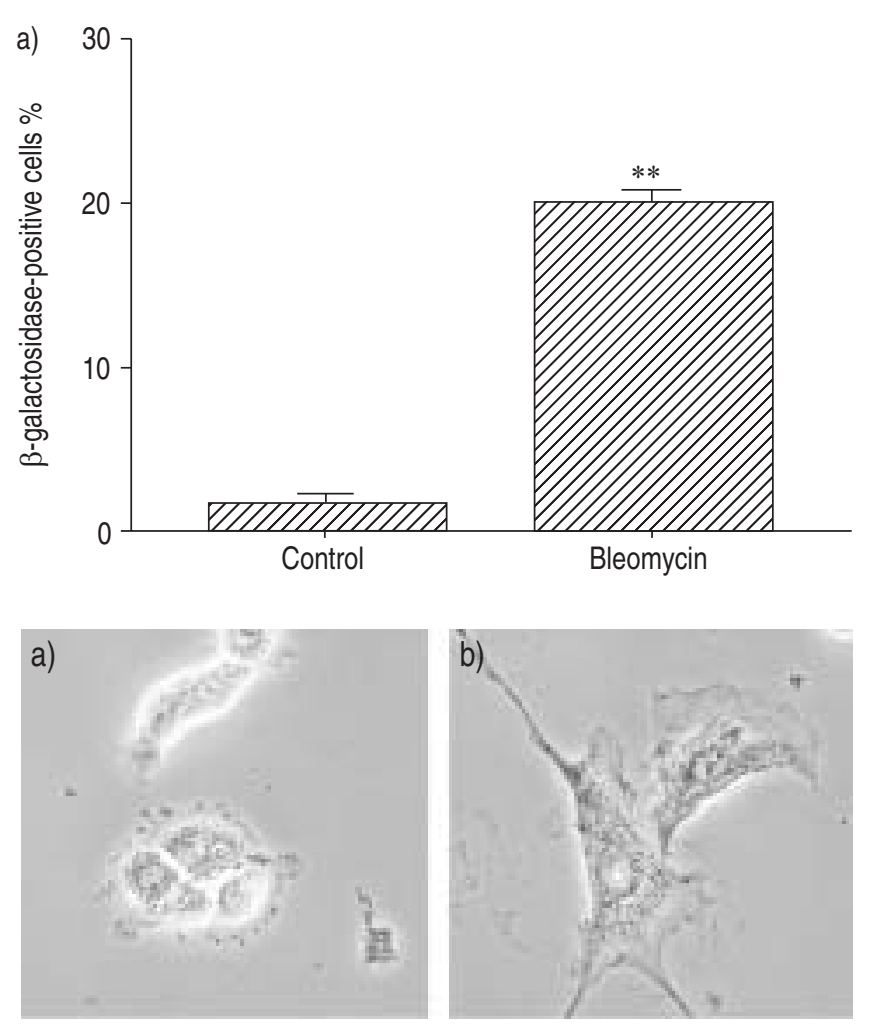

Fig. 4. - a) Senescence-associated $\beta$-galactosidase activity and b, c) cell morphology in primary rat type II cells treated with or without bleomycin $\left(5 \mu \mathrm{g} \cdot \mathrm{mL}^{-1}\right)$ for $24 \mathrm{~h}$ (b shows untreated cells and $\mathrm{c}$ bleomycin-treated cells); **: $\mathrm{p}<0.01$ versus cells not treated with bleomycin. Data are presented as mean \pm SEM for four samples. The results are representative of two experiments.

telomere shortening or by telomere-independent signals, such as DNA damage and oxidative stress [9]. The present study using alveolar epithelial cells supports previous findings showing that DNA damaging agents, such as bleomycin, actinomycin D, and etoposide, induce a senescence phenotype in normal fibroblasts and some tumour cell lines [21].

Regeneration of the injured epithelium involves the proliferation of alveolar type II cells. After an intratracheal injection of bleomycin, the early death of alveolar type I cells is followed by the attempted proliferation of type II cells [22]. However, the proliferative capacity of the type II cells following bleomycin-induced injury is seriously affected, resulting in the absence of appropriate re-epithelialisation; the lack of re-epithelialisation allows activated fibroblasts to migrate, through defects in the epithelium, from the interstitial in the intraluminal compartments [22]. This pathway of impaired epithelial cell regeneration leading to pulmonary fibrosis is supported by previous findings showing that the enhancement of epithelial proliferation by treatment with keratinocyte growth factor or hepatocyte growth factor ameliorates bleomycininduced pulmonary fibrosis in mice $[23,24]$. These findings suggest that the proliferation of alveolar epithelial cells is important for preventing the progress of bleomycin-induced pulmonary fibrosis. In this context, the present study suggests that the proliferation of alveolar epithelial cells may be limited as a result of cellular senescence, providing a new insight into the mechanism of pulmonary fibrosis.

The induction of cellular senescence does not indicate that cellular functions are depressed. For example, many studies have shown that senescent cells produce higher levels of matrix metalloproteinases, such as collagenases and stromelysin, and profibrotic cytokines, such as interleukin-1 $\beta$ and transforming growth factor- $\beta$ (TGF- $\beta$ ), than normal cells [25-27]. These studies suggest that senescent cells may be involved not only in impaired tissue regeneration but also in the inflammatory response and extracellular matrix remodelling. Future studies are needed to examine whether senescence of alveolar epithelial cells is associated with functional abnormalities.

The limitation of this study is that the authors used A549 cells, immortalised cancer cells that lack the proliferative controls found in nontransformed cells. This notion is important because bleomycin is an anticancer drug which causes DNA damage in cancer cells. It is therefore difficult to extrapolate the present studies in vitro findings with A549 cells to normal alveolar epithelial cells. However, the authors found that treatment of primary rat type II cells with bleomycin also induced a senescence phenotype characterised by an increased SA $\beta$-gal activity and a flat and enlarged cell morphology. The authors also found that an in vivo exposure of bleomycin in mice caused an increase in SA $\beta$-gal activity in normal alveolar epithelial cells, suggesting that the response of A549 cells to bleomycin is not very different from that of normal alveolar epithelial cells.

The second limitation of this study is that the authors used an SA $\beta$-gal staining method to identify senescent cells in lung tissue [17]. This method has been widely used by many investigators who have shown a good correlation between SA $\beta$-gal activity and the onset of senescence in vitro and in vivo $[12,13,15]$. However, SA $\beta$-gal activity may not be specific for senescence in all tissues, as it may also represent the expression of normal endogenous lysosomal acid $\beta$-galactosidase and may not distinguish senescent cells from quiescent or terminally differentiated cells $[16,28]$. In fact, the current authors found that alveolar macrophages in normal murine lungs also exhibits SA $\beta$-gal activity (fig. 5n), suggesting that this marker must be used cautiously. The current authors also do not exclude the possibility that bleomycin may directly affect the SA $\beta$-gal activity. The expression of SA $\beta$-gal may also be different in rodent and human cells. An alternative method of detecting senescent cells in vivo would be the determination of telomere length by in situ hybridisation. However, this method is not suitable for the detection of telomere-independent senescence induced by DNA damage and oxidative stress, in the case of bleomycin. Thus, an absolute marker enabling the specific identification of cellular senescence in vivo, particularly stress-induced senescence, is not yet available. In this context, the present authors do not completely exclude the possibility that SA $\beta$-gal activity might also reflect cell conditions other than senescence.

The third limitation of this study is that although bleomycin-induced pulmonary fibrosis in rodents has often been used as a model of human pulmonary fibrosis, this model does not resemble the histological and physiological features of human idiopathic pulmonary fibrosis (IPF). For example, a recent study showed that the early stages of bleomycin-induced lung injury in rats mimic diffuse alveolar damage (DAD), whereas the later, more chronic stages exhibit focal peribronchialar inflammation and fibrosis associated with paracicatrical emphysematous changes [29]. In humans, bleomycin-induced lung injury has been shown to resemble DAD or bronchiolitis obliterans organising pneumonia [29], but not IPF. Thus, the bleomycin-induced model resembles only a particular group of interstitial lung diseases in humans, mainly those associated with peribronchovascular involvement [30]. Therefore, extrapolation of the present findings in bleomycin-induced pulmonary fibrosis to the situation in humans needs to be done with great caution.

Although the present study has several limitations, the 

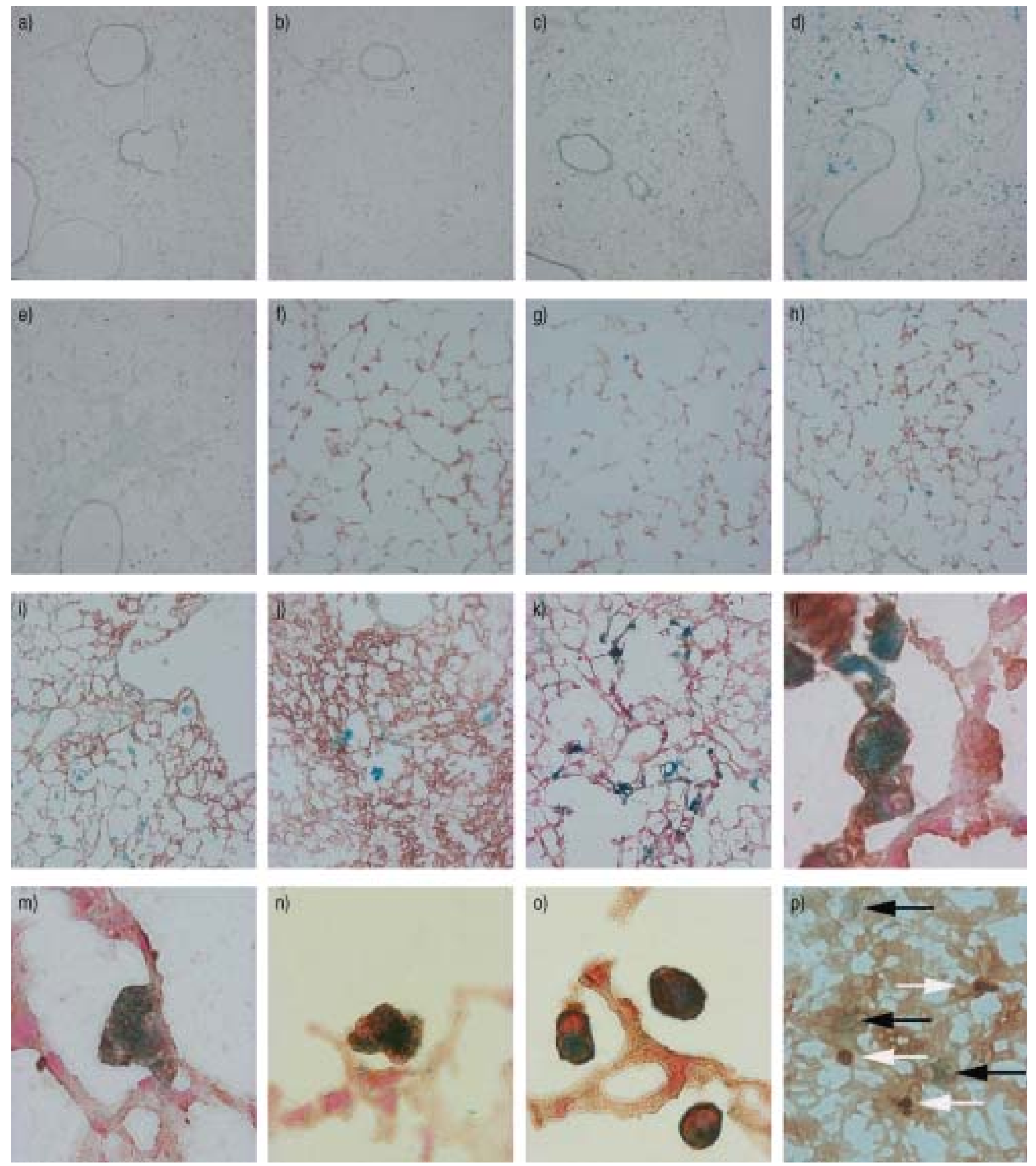

Fig. 5. - Senescence-associated $\beta$-galactosidase (SA $\beta$-gal) activity in lung tissue sections from mice sacrificed before (a, f, n) and at 1 day (b, g), 4 days $(\mathrm{c}, \mathrm{h}), 7$ days $(\mathrm{d}, \mathrm{i}, \mathrm{k}, \mathrm{l}, \mathrm{m}, \mathrm{o}, \mathrm{p})$, and 21 days $(\mathrm{e}, \mathrm{j})$ after an intratracheal injection of bleomycin $\left(5 \mathrm{U} \cdot \mathrm{kg}^{-1}\right.$ body weight). At $4 \mathrm{~h}$ prior to sacrifice the mice received an intraperitoneal injection of $30 \mu \mathrm{g}$ of bromodeoxyuridine (BrdU). a)-e) show SA $\beta$-gal staining (blue colour). f)-j) show SA $\beta$-gal staining followed by antilaminin immunostaining (brown colour) to identify the alveolar structure. k) and 1) show SA $\beta$-gal staining followed by antipancytokeratin immunostaining (brown colour) to identify the epithelial cells. Cell nuclei were stained with a nuclear fast red solution. m) shows SA $\beta$-gal staining followed by anti-SP-A immunostaining (brown colour) to identify the type II cells, the cells nuclei were stained with a nuclear fast red solution. n) and o) show SA $\beta$-gal staining followed by anti-CD45 immunostaining to identify haematopoietic cells (brown colour). Cell nuclei were stained with a nuclear fast red solution. Intraluminal alveolar macrophages are positively stained for SA $\beta$-gal. p) SA $\beta$-gal staining (black arrows) followed by anti-BrdU immunostaining (white arrows) shows that the SA $\beta$-gal-stained cells do not incorporate BrdU. 

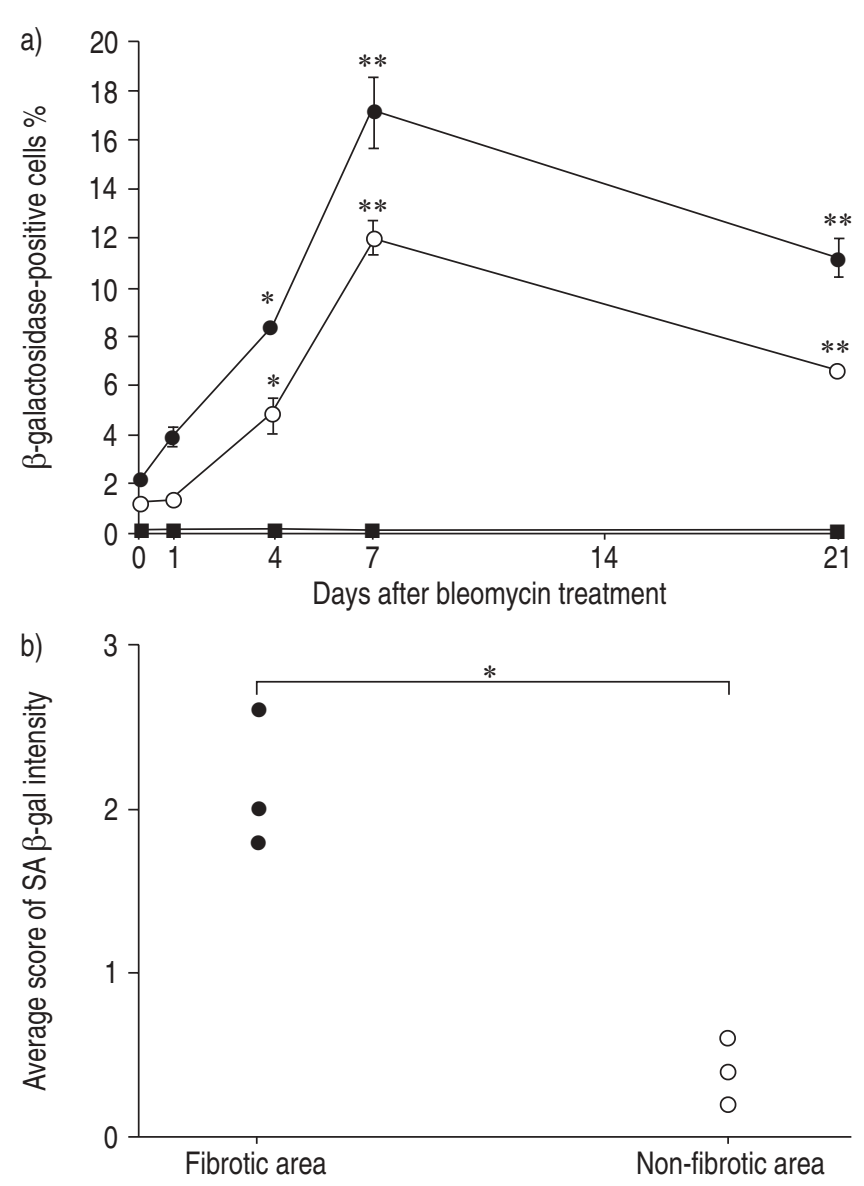

Fig. 6. - Semi-quantitative analyses of senescence-associated $\beta$ galactosidase (SA $\beta$-gal) activity in lung tissue sections. a) Time course of SA $\beta$-gal activity in lung tissue sections from mice sacrificed before (day 0) and at days 1, 4, 7, and 21 after an intratracheal injection of bleomycin $(\boldsymbol{Q}$ : cells positive for both SA $\beta$-gal activity and anti-SP-A immunostaining; $\bigcirc$ : cells positive for both SA $\beta$-gal activity and antipancytokeratin immunostaining; $\mathbf{\square}$ : cells positive for both SA $\beta$-gal activity and anti-CD31 immunostaining). All data are mean \pm SEM for three mice at each time point. *: $\mathrm{p}<0.05$, **: $\mathrm{p}<0.01$ versus day 0 . b) The average grade of SA $\beta$-gal intensity in relation to fibrosis in lungs of mice at 21 days after an intratracheal injection of bleomycin. Individual data from three mice are indicated. $*$ : $\mathrm{p}<0.05$.

current authors propose that epithelial senescence may be involved in bleomycin-induced fibrosis and possibly, in other types of pulmonary fibrosis. In pulmonary fibrosis, repeated deoxyribonucleic acid (DNA) and oxidative damage promotes epithelial cell senescence, thereby limiting their capacity to proliferate. The continuous proliferation of epithelial cells required to regenerate the damaged epithelium also accelerates telomere shortening and promotes epithelial cell senescence. When the epithelial cells reach the senescence stage, epithelial regeneration ceases and fibrosis progresses. This model provides a plausible explanation for the chronic nature of pulmonary fibrosis, which evolves slowly over many years. A detailed characterisation of cellular senescence in lung tissue samples should help to provide a better understand the pathogenesis of pulmonary fibrosis, and possibly, to identify new targets for treatment.

Acknowledgements. The authors are very grateful to M. Shino and Y. Sugimura for their excellent technical assistance.

\section{References}

1. Gross TJ, Hunninghake GW. Idiopathic pulmonary fibrosis. $N$ Engl J Med 2001; 345: 517-525.

2. Crystal RG, Bitterman PB, Rennard SI, Hance AJ, Keogh BA. Interstitial lung diseases of unknown cause. Disorders characterized by chronic inflammation of the lower respiratory tract (first of two parts). N Engl J Med 1984; 310: 154 166.

3. Crystal RG, Bitterman PB, Rennard SI, Hance AJ, Keogh BA. Interstitial lung diseases of unknown cause. Disorders characterized by chronic inflammation of the lower respiratory tract. $N$ Engl J Med 1984; 310: 235-244.

4. Selman M, King TE, Pardo A. Idiopathic pulmonary fibrosis: prevailing and evolving hypotheses about its pathogenesis and implications for therapy. Ann Intern Med 2001; 134: 136-151.

5. Kawanami O, Ferrans VJ, Crystal RG. Structure of alveolar epithelial cells in patients with fibrotic disorders. Lab Invest 1982; 46: 39-53.

6. Basset F, Ferrans VJ, Soler P, Takemura T, Fukuda Y, Crystal RG. Intraluminal fibrosis in interstitial lung disorders. Am J Pathol 1986; 122: 443-461.

7. Qunn L, Takemura T, Ikushima S, et al. Hyperplastic epithelial foci in honeycomb lesions in idiopathic pulmonary fibrosis. Virchows Arch 2002; 441: 271-278.

8. Hayflick L, Moorhead PS. The limited in vitro lifetime of human diploid cell strains. Exp Cell Res 1961; 25: 585-621.

9. Marcotte R, Wang W. Replicative senescence revisited. $J$ Gerontol 2002; 57A: B257-B269.

10. Hornsby PJ. Cellular senescence and tissue aging in vivo. $J$ Gerontol 2002; 57A: B251-B256.

11. Stanley A, Osler T. Senescence and the healing rates of venous ulcers. J Vasc Surg 2001; 33: 1206-1211.

12. Wiemann SU, Satyanarayana A, Tsahuridu M, et al. Hepatocyte telomere shortening and senescence are general markers of human liver cirrhosis. FASEB J 2002; 16: 935-942.

13. Minamino T, Miyauchi H, Yoshida T, Ishida Y, Yoshida H, Komuro I. Endothelial cell senescence in human atherosclerosis: role of telomere in endothelial dysfunction. Circulation 2002; 105: 1541-1544.

14. Aoshiba K, Yasui S, Tamaoki J, Nagai A. The Fas-Fas ligand system is not required for bleomycin-induced pulmonary fibrosis in mice. Am J Respir Crit Care Med 2000; 162: 695-700.

15. Dobbs LG, Geppert EF, Williams MC, Greenleaf RD, Mason RJ. Metabolic properties and ultrastructure of alveolar type II cells isolated with elastase. Biochim Biophys Acta 1980; 618: 510-523.

16. Kurz DJ, Decary S, Hong Y, Erusalimsky JD. Senescenceassociated $\beta$-glactosidase reflects an increase in lysosomal mass during replicative ageing of human endothelial cells. J Cell Sci 2000; 113: 3613-3622.

17. Dimri GP, Lee X, Basile G, et al. A biomarker that identifies senescent human cells in culture and in aging skin in vivo. Proc Natl Acad Sci USA 1995; 92: 9363-9367.

18. Robbins E, Levine EM, Eagle H. Morphologic changes accompanying senescence of cultured human diploid cells. J Exp Med 1970; 131: 1211-1222.

19. Wang $Y$, Blandino G, Givol D. Induced $\mathrm{p} 21^{\text {waf }}$ expression in H1299 cell line promotes cell senescence and protects against cytotoxic effect of radiation and doxorubicin. Oncogene 1999; 18: 2643-2649.

20. Skudlarek MD, Swank RT. Biosynthesis of two lysosomal enzymes in macrophages. Evidence for a precursor of betagalactosidase. J Biol Chem 1979; 254: 9939-9942.

21. Miller YE, Walker SR, Spencer JS, Kubo RT, Mason RJ. Monoclonal antibodies specific antigens expressed by rat type II alveolar epithelial and nonciliated bronchiolar cells. Exp Lung Res 1989; 15: 635-649.

22. Kawamoto M, Fukuda Y. Cell proliferation during the 
process of bleomycin-induced pulmonary fibrosis in rats. Acta Pathol Jpn 1990; 40: 227-238.

23. Yi ES, Williams ST, Lee $\mathrm{H}$, et al. Keratinocyte growth factor ameliorates radiation- and bleomycin-induced lung injury and mortality. Am J Pathol 1996; 149: 19631970.

24. Dohi M, Hasegawa $\mathrm{T}$, Yamamoto $\mathrm{K}$, Marshall BC. Hepatocyte growth factor attenuates collagen accumulation in a murine model of pulmonary fibrosis. Am J Respir Crit Care Med 2002; 162: 2302-2307.

25. Sottile J, Mann DM, Diemer V, Millis AJ. Regulation of collagenase and collagenase mRNA production in early- and late-passage human diploid fibroblasts. J Cell Physiol 1989; 138: 281-290.

26. Kumar S, Millis AJ, Baglioni C. Expression of interleukin 1inducible genes and production of interleukin 1 by aging human fibroblasts. Proc Natl Acad Sci USA 1992; 89: 46834687.

27. Ding G, Franki N, Kapasi AA, Reddy K, Gibbons N, Singhal PC. Tubular cell senescence and expression of TGFbeta1 and p21 (WAF1/CIP1) in tubulointerstitial fibrosis of aging rats. Exp Mol Pathol 2001; 70: 43-53.

28. Severino J, Allen RG, Balin S, Balin A, Cristofalo VJ. Is beta-galactosidase staining a marker of senescence in vitro and in vivo? Exp Cell Res 2000; 257: 162-171.

29. Rossi SE, Evasmus FF, McAdams HP, Sporn TA, Goodman PC. Pulmonary drug toxicity: radiologic and pahologic manifestations. RadioGraphics 2000; 20: 1245-1259.

30. Borzone G, Moreno R, Urrea R, Meneses M, Oyarzun M, Lisboa C. Bleomycin-induced chronic damage does not resemble human idiopathic pulmonary fibrosis. Am J Respir Crit Care Med 2001; 163: 1648-1653. 